\title{
WHU VHF radar observations of the diurnal tide and its variability in the lower atmosphere over Chongyang $\left(114.14^{\circ} \mathrm{E}, 2^{29.53}{ }^{\circ} \mathrm{N}\right)$, China
}

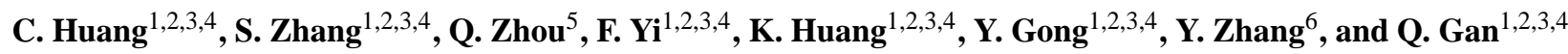 \\ ${ }^{1}$ School of Electronic Information, Wuhan University, Wuhan, Hubei, China \\ ${ }^{2}$ Key Laboratory of Geospace Environment and Geodesy, Ministry of Education, Wuhan, Hubei, China \\ ${ }^{3}$ State Observatory for Atmospheric Remote Sensing, Wuhan, Hubei, China \\ ${ }^{4}$ State Key Laboratory of Information Engineering in Surveying, Mapping and Remote Sensing, \\ Wuhan University, Wuhan, Hubei, China \\ ${ }^{5}$ Electrical and Computer Engineering Department, Miami University, Oxford, Ohio, USA \\ ${ }^{6}$ College of Hydrometeorology, Nanjing University of Information Science and Technology, Nanjing, China
}

Correspondence to: S. Zhang (zsd@whu.edu.cn)

Received: 23 February 2015 - Revised: 10 June 2015 - Accepted: 7 July 2015 - Published: 23 July 2015

\begin{abstract}
The diurnal tide (DT) and its variability in the lower atmosphere over Chongyang $\left(114.14^{\circ} \mathrm{E}, 29.53^{\circ} \mathrm{N}\right)$ were studied based on the newly established Wuhan University (WHU) VHF radar observations with the height intervals of $0.145 \mathrm{~km}$ (below $9 \mathrm{~km}$ ) and $0.58 \mathrm{~km}$ (above $9 \mathrm{~km}$ ) in the whole year of 2012. We find that the DT was the dominant tidal component and showed remarkable height and season variations. A prominent seasonally dependent height variability characteristic is that maximum DT amplitude usually occurs around $6 \mathrm{~km}$ in the winter and spring months, which might be due to the tidal wave energy concentration arising from the reflections from the strong eastward tropospheric jet around $13 \mathrm{~km}$ and the ground surface. Our results suggest that the background wind is a crucial cause for height variability and seasonal variability of DT. In April 2012, a notable strengthening of DT is observed. Meanwhile, the significant higher harmonics of tides, i.e., the semidiurnal, terdiurnal, and even quarterdiurnal tides, can also be observed, which has seldom been reported. Interestingly, these four tidal components displayed consistent short-term variability, implying that they were excited by the same dramatically varying tidal source. In addition, we identified two symptoms of the coupling of DT and planetary waves (PWs), which can also lead to the short-term DT variability. One is the sum and difference interactions between DT and PWs, causing the tidal amplitude short-term variability as a consequence of the energy exchange among the interacting waves. The
\end{abstract}

other one is the modulation of DT by PWs, leading to that the amplitude of DT varies with the periods of the PWs.

Keywords. Meteorology and atmospheric dynamics (middle atmosphere dynamics; waves and tides)

\section{Introduction}

Atmospheric waves, including tides, gravity waves (GWs), and planetary waves (PWs), are ubiquitous in the atmosphere and are believed to exert a substantial impact on local and global atmospheric climatology (Alexander and Pfister, 1995; Alexander, 1998; Batista et al., 2004; Kishore et al., 2004). Atmospheric tides are global-scale waves with periods that are harmonics of a solar day, which are closely related to the large-scale circulation patterns and strongly modulate GWs' energy and momentum flux. The lower atmosphere is one of the primary tidal source regions. Absorption of solar radiation by tropospheric $\mathrm{H}_{2} \mathrm{O}$ and stratospheric $\mathrm{O}_{3}$ and latent heating associated with deep tropical convection in the troposphere are the most well-known sources of tidal excitation (Hagan et al., 1995, 2001; Hagan and Forbes, 2002; Sakazaki et al., 2010). Under the assumption of energy conservation, the amplitudes of tides excited in the lower atmosphere grow with increasing altitude due to the exponential decrease in atmospheric density when they propagate upward 
to the middle and upper atmosphere, and become one of the most striking features of wind field there. Moreover, given that gravity waves play a crucial role in determining local and global atmospheric dynamics, as a portion of background wind in which gravity waves propagate, tidal wind has a significant impact on gravity waves (Beldon and Mitchel, 2010; Huang, C. M. et al., 2013). Therefore, the tides generated in the lower atmosphere can exert a critical influence on not only the structure and characteristic of the lower atmosphere but also on those of the middle and upper atmosphere.

Tides propagating in the atmosphere are dominated by tidal sources and background winds, the seasonal variability of which would manipulate the seasonal variability of tides (Hagan et al., 1997; Forbes et al., 1997; McLandress, 2002; Zhang et al., 2012). On the basis of observational and theoretical research in the recent decades, comprehensive understanding about the seasonal variability of tidal sources and background winds has been achieved (Hagan et al., 2001), and the primary seasonal variability of tides has been subsequently demonstrated. As the most widely accepted tidal models, the global-scale wave models (GSWMs) can provide the monthly averaged tides in the height range of 0 $124 \mathrm{~km}$ and clearly display the latitude and season variability of tides. However, some observational and numerical studies also verify that tides, especially the diurnal tide, also exhibit remarkable local variability, e.g., prominent amplitude peaks in the middle troposphere (Huang et al., 2009), as well as short-term (shorter than 1 month) variability arising from wave-wave interactions (Beard et al., 1999, 2001; Huang et al., 2012; Pancheva et al., 2002; Pancheva, 2006). The local and short-term variability of tides can influence not only the local dynamics but also the dynamics in a wider region in both the vertical and horizontal spatial scales by modulating the activity of GWs or interaction with PWs. It should be noted that the local and short-term variability of tides cannot be described by GSWMs. Therefore, more investigations are needed to reveal the tidal local and short-term variability and the involved mechanisms.

Due to their significant amplitudes, tides in the mesosphere and lower thermosphere (MLT) have been extensively investigated, while tides with weak amplitudes in the lower atmosphere and their variability have not been adequately studied. Satellite observations have contributed greatly to the study of global atmospheric tides. However, most satellites are only able to provide the tidal information with high precision above the lower stratosphere (Zhang et al., 2006). For example, SABER (Sounding of the Atmosphere using Broadband Emission Radiometry) can only explore the regions above $20 \mathrm{~km}$. Few satellite observations were able provide the information about tides in the troposphere, until 2002, when the Constellation Observing System for Meteorology, Ionosphere and Climate (COSMIC) was put into operation and temperature in the troposphere was measured. However, even COSMIC observations in the lower atmosphere can only provide high-accuracy temperature profiles in the height range of $8-40 \mathrm{~km}$, and it is still hard to acquire data with high precision below $8 \mathrm{~km}$ (Pirscher et al., 2010). Moreover, although the satellite observations can effectively reveal the climatology of global tides, limited by the local time resolution, they are difficult to be applied in exploring the short-term variability of local tides.

Due to the weak amplitudes of tides in the lower atmosphere, continuous observational data with high precision are hard to acquire, and relative investigations are very rare. Radiosonde observations can provide horizontal wind and temperature from the ground up to about $30 \mathrm{~km}$ (Zhang et al., 2012, 2013), but routine measurements on a twice-daily basis have rarely been used to reveal the characteristics of tides (Wallace and Hartranft, 1969; Wallace and Tadd, 1974). Some intensive radiosonde campaigns (Tsuda, et al., 1994a, 1994b; Seidel et al., 2005; Zhang et al., 2008; Huang et al., 2009) can make a contribution to our understanding of local tides and their variability. However, these intensive observations are generally sparse and there are no long-term continuous intensive observations at all.

VHF radars are capable of continually observing winds, and their data can be utilized to effectively study the season and short-term variability of local tides. However, the VHF data are still not abundant and the studies are inadequate (Williams and Avery, 1992; Sasi et al., 2001; Riggin et al., 2002; Vaughan and Worthington, 2007; Ramkumar et al., 2010; Chandrasekhar Sarma et al., 2011; Sakazaki et al., 2010). Supported by the Meridian Space Weather Monitoring Project, the Wuhan University (WHU) VHF radar was established in 2011 at Chongyang $\left(114.14^{\circ} \mathrm{E}, 29.53^{\circ} \mathrm{N}\right)$. In the present paper, we focus primarily on the diurnal tide (DT) and its variability in the lower atmosphere revealed by the WHU VHF radar observations and attempts to expose the mechanisms accounting for the local short-term variability of the DT. The data set utilized in this paper is described in detail in the following section. The characteristics of the monthly averaged DT and its season and height variability are given in Sect. 3. The short-term variability of DT resulting from dramatically varying tidal source and the coupling of DT and PWs are discussed in Sects. 4 and 5, respectively. In the last section, we give a brief summary of our observations.

\section{Data description}

The WHU VHF radar was established at Chongyang, Hubei Province, China, in September 2011, with geomagnetic latitude of about $23^{\circ}$. After 3-month trial observations, it was put into routine operation in 2012. A detailed description of the radar including its specifications, signal processing, and data analysis is given by Zhao et al. (2013). Here we only provide the primary parameters of the radar used for our study: the operating frequency is $53.8 \mathrm{MHz}$, the peak power is $172 \mathrm{~kW}$, and the radar antenna system arranged in $24 \times 24$ square matrix is composed of 576 Yagi-Uda units with horizontal lin- 

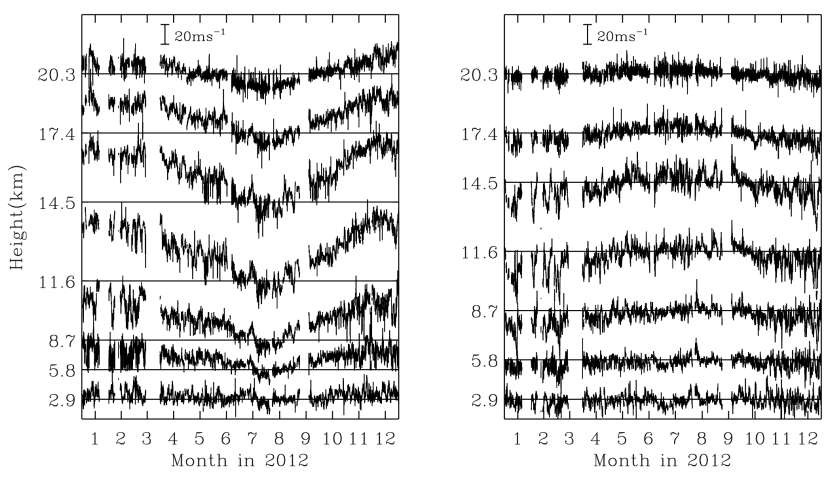

Figure 1. The raw time series for the zonal wind (left) and meridional wind (right) at every $2.9 \mathrm{~km}$ in the whole year of 2012. The horizontal lines denote the zero values.

ear polarization. This radar operates in three separate modes, providing the wind measurements in the height ranges of $3.5-9.0 \mathrm{~km}$ (low mode), $11.0-22.6 \mathrm{~km}$ (middle mode) and $60.0-90.0 \mathrm{~km}$ (high mode). For the low, middle, and high modes, the height resolutions are respectively $0.145,0.58$, and $1.13 \mathrm{~km}$, while the time resolutions are all $30 \mathrm{~min}$.

Due to the lack of effective echoes from the mesosphere in the high mode, the mesospheric wind sounding is discontinuous; thus, in this study we focus on the horizontal winds revealed by the low- and middle-mode observations. The data utilized in this paper consist of the lower atmospheric (3.5$9.0 \mathrm{~km}$ and $11.0-22.6 \mathrm{~km}$ ) horizontal wind measurements in the whole year of 2012. The measurements are basically continuous in the whole months except January and March, in which there are only about 20- and 14-day continuous observations, respectively. Moreover, resulting from the occasional weak echoes, there are missing data from time to time in every month, leading to uneven time intervals. Fortunately, few time intervals are longer than $6 \mathrm{~h}$ and rarely longer than $24 \mathrm{~h}$. If the time interval is greater than $6 \mathrm{~h}$, it is marked as no measurement. Otherwise, we would supplement the missing data by linear interpolation. The portion of gaps longer than $6 \mathrm{~h}$ in each month is basically smaller than $20 \%$, except for June $(30.5 \%)$ and September $(43.0 \%)$. Fortunately, our main conclusions are not affected by the results in these two months. Our investigation was focused on winter months, as well as April and May. In these months, the portions of gaps longer than $6 \mathrm{~h}$ are small. Since the accuracy of radical velocity is estimated to be about $0.2 \mathrm{~m} \mathrm{~s}^{-1}$ according to the radar specification, the horizontal wind accuracy should be better than this estimated value and on the order of $10^{-1} \mathrm{~m} \mathrm{~s}^{-1}$. Furthermore, the resulting error of the monthly averaged values should be less than $10^{-1} \mathrm{~m} \mathrm{~s}^{-1}$.

Figure 1 presents the raw time series for the zonal wind and meridional wind at every $2.9 \mathrm{~km}$ in April (from day 92 to 121 in 2012). From this figure, we can see that these two physical quantities are obviously disturbed by many waves with different periods. Subsequently, we provide the
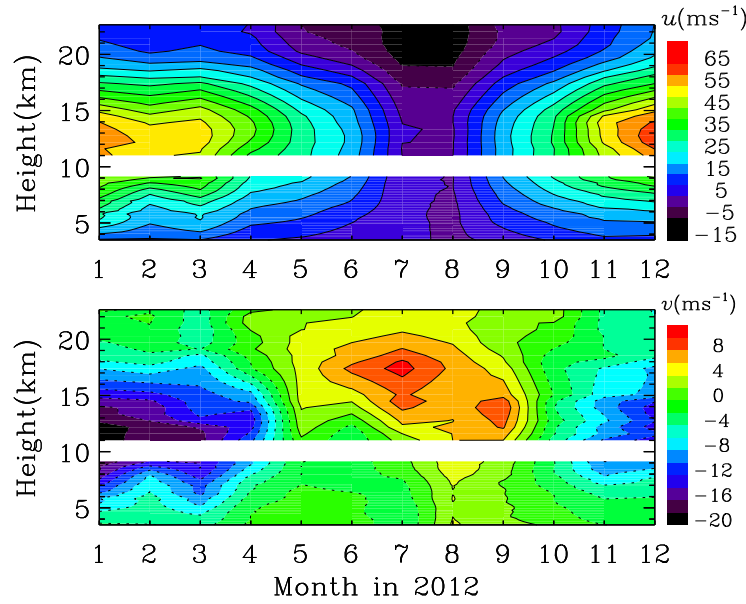

Figure 2. Monthly averaged background zonal wind (top) and meridional wind (bottom) in 2012.

monthly averaged zonal wind and meridional wind at each altitude for the low and middle modes in 2012 in Fig. 2. The characteristics of the background horizontal wind over Chongyang in 2012 can be summarized as follows: the background zonal wind varies in the range of $-13.0-64.0 \mathrm{~m} \mathrm{~s}^{-1}$ and has an obvious annual cycle. It is always eastward at all the shown heights in the months from October to April, while in months from May to September, westward background zonal wind occurs. In all months except for July and August, the background zonal wind increases with altitude from $3.5 \mathrm{~km}$ up to about $12-13 \mathrm{~km}$ and then decreases with altitude, which is the typical tropospheric zonal wind structure at middle latitudes. Clearly, there exists a strong eastward tropospheric jet at the heights around $12-13 \mathrm{~km}$ in winter months, especially in December, with maximum value of $63.98 \mathrm{~m} \mathrm{~s}^{-1}$ at $12.75 \mathrm{~km}$. The largest westward zonal wind, i.e., $-13.0 \mathrm{~m} \mathrm{~s}^{-1}$, occurs at $22.6 \mathrm{~km}$ in August. Compared with the zonal wind, the meridional wind is rather weaker and less than $20 \mathrm{~m} \mathrm{~s}^{-1}$. In almost the whole altitude range, the meridional wind fields are basically southward in winter and northward in summer. The strongest northward wind occurs at $17.39 \mathrm{~km}$ in July, with a maximum value of $8.75 \mathrm{~m} \mathrm{~s}^{-1}$, while the strongest southward wind occurs at $11.01 \mathrm{~km}$ in January, with a minimum value of $-19.77 \mathrm{~m} \mathrm{~s}^{-1}$. The characteristics of the background horizontal winds are similar to those revealed by radiosonde observations at middle latitudes (Zhang and Yi, 2007; Zhang et al., 2012).

For comparison, we downloaded MERRA (the Modern Era Retrospective-analysis for Research and Applications) data set "inst6_3d_ana_Nv" from http://disc.sci.gsfc.nasa. gov/, which provides the 6-hourly instantaneous eastward wind and northward wind at the native horizontal resolution of $2 / 3^{\circ}$ longitude by $1 / 2^{\circ}$ latitude and at 72 vertical model levels from 985 to $0.01 \mathrm{hPa}$. 


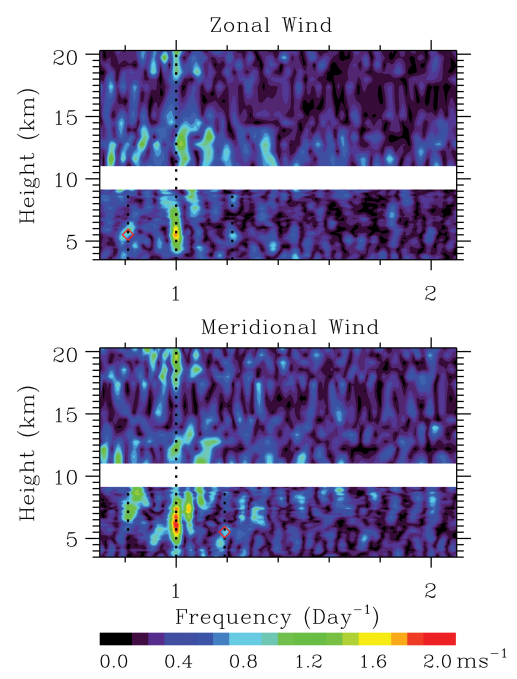

Figure 3. Lomb-Scargle periodogram of high-pass-filtered zonal wind (top) and meridional wind (bottom) in April 2012. The maximum spectral magnitudes for the zonal and meridional winds are 1.84 and $2.07 \mathrm{~m} \mathrm{~s}^{-1}$, respectively. The two red diamonds represent the sidelobes at $5.51 \mathrm{~km}$.

\section{Monthly averaged DT}

The WHU VHF radar observations provide a $30 \mathrm{~min}$ time resolution and allow us to study the diurnal oscillation in the temporal domain. For exploring the tidal disturbances, we apply a high-pass filter with a cutoff at $36 \mathrm{~h}$ for the time series of the raw data of the zonal wind and meridional wind at each height. A Lomb-Scargle periodogram analysis (Scargle, 1982) is performed on the resultant time series. Figure 3 is the frequency spectra at each sampling height in April 2012. The top and bottom panels are for the zonal wind and meridional wind, respectively, and the spectral magnitudes are normalized. It can be clearly observed from this figure that dominant diurnal oscillations exist. Since the periods of GWs are shorter than $24 \mathrm{~h}$ at midlatitudes defined by the local Coriolis frequency, and the results fitted from consecutive 1-month measurements would smooth out the intermittently and randomly occurring GWs, we take the diurnal oscillation as DT here. Below $5 \mathrm{~km}$ and in the range of $13.5-16.5 \mathrm{~km}$, the DT is very weak. A noticeable feature that can be observed from Fig. 3 is that there are some significant values scattering over a $24 \mathrm{~h}$ period, which may be the symptom of the secondary waves generated by the planetary wave-tidal wave interaction (Huang, K. M. et al., 2013) and will be discussed in Sect. 5.

In order to get more information about the DT, we harmonically fit the DT oscillation from the time series of the zonal wind and meridional wind in every month of 2012 to obtain the monthly averaged DT amplitude and phase. It should be noted that only the monthly averaged characteristics of the DT are concerned here, and day-to-day variation is discussed in the next paragraph. The fitted amplitudes of the DT in
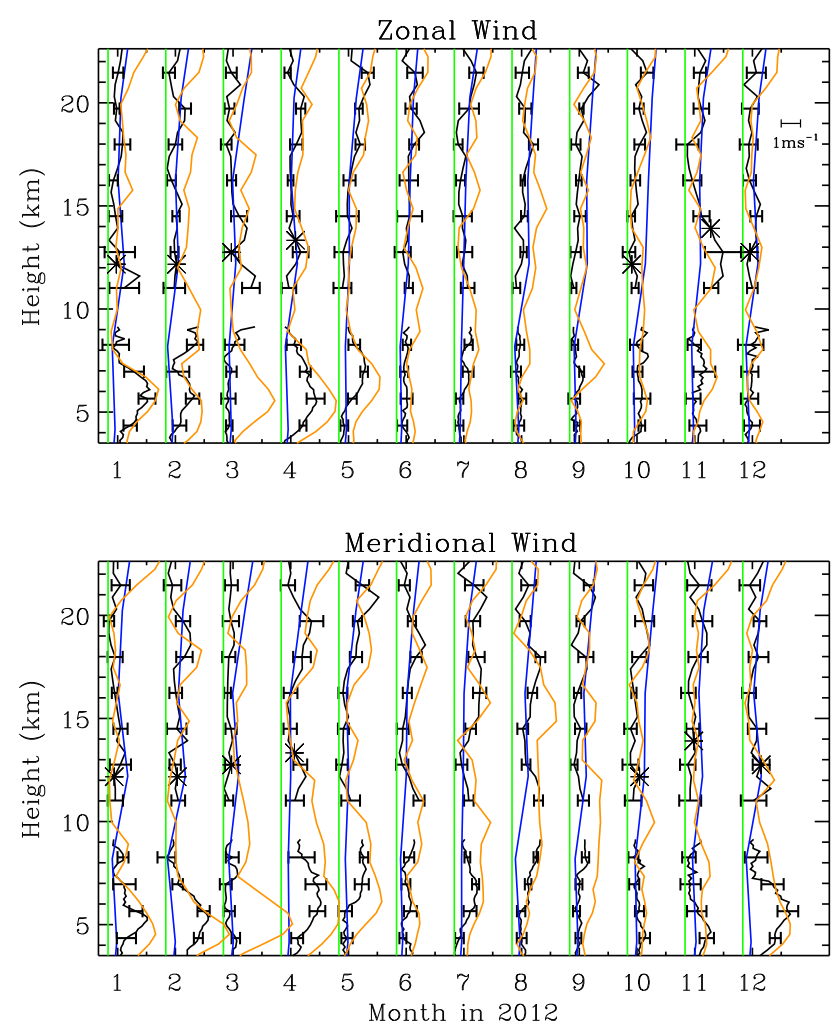

Figure 4. Comparison between the fitted monthly amplitude of the diurnal tide in 2012 (black curve along with error bars) and those amplitudes from the MERRA data set "inst6_3d_ana_Nv" (orange) and GSWM-02 (blue) in zonal wind (top) and meridional wind (bottom). The green vertical lines represent zeros. The asterisks represent the heights of the tropospheric jet.

every month of 2012 are plotted in Fig. 4. For the purpose of comparison, the numerical model results from GSWM-02 (Hagan and Forbes, 2002) are also given in this figure. The GSWM-02 presents the calculation incorporating migrating tide and nonmigrating tide associated with tropospheric latent heat processes. Moreover, we downloaded MERRA data "inst6_3d_ana_Nv" from the internet and extracted the diurnal tidal winds over Chongyang in the year 2012, which are shown in this figure by dotted lines. Generally speaking, in the lower stratosphere (above $17 \mathrm{~km}$ ), the observed wind amplitude profiles agree well with the GSWM-02 but show obvious departure below $9 \mathrm{~km}$, where the observed amplitudes are evidently larger than the GSWM-02 predictions but much closer to the MERRA results. The observed tide displays fairly significant height variations, which has been revealed by previous intensive radiosonde observations (Tsuda et al., 1994a; Huang et al., 2009). In the winter and spring months, there exist remarkable maximums below $8 \mathrm{~km}$ in the zonal and meridional winds, which agrees with our previous radiosonde observations at middle latitudes (Huang et al., 2009) and the MERRA results. However, possibly because only 14-day continuous observations in March could 

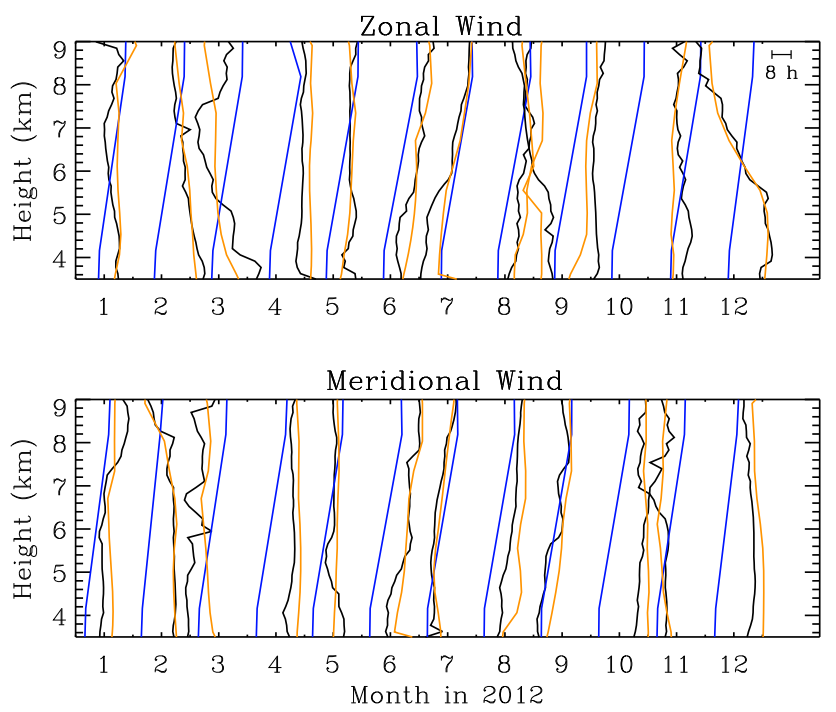

Figure 5. Similar to Fig. 4, but for the DT phase in the height range of $3.5-9.0 \mathrm{~km}$.

not fully reflect the real DT characteristics in this month, the maximum of DT below $8 \mathrm{~km}$ in March was absent in our observations but shown in both zonal and meridional winds in MERRA data. It seems that it is a common characteristic for the DT at middle latitudes to show maximums at these heights. Another prominent characteristic regarding the height variations for DT amplitudes is that, at the winter tropospheric jet heights, around $12-13 \mathrm{~km}$, they are very small and closer to the GSWM-02 and MERRA results. In summer months, there is no maximum below $8 \mathrm{~km}$ and the amplitude is weak from $3.5 \mathrm{~km}$ up to around $12-13 \mathrm{~km}$.

The height and season variations in the DT amplitude may be related to the tropospheric jet. Considering the DT might contain westward-propagating components, we speculate that the DT may have a standing wave structure due to its reflection between the ground and the jet, and then the wave energy is concentrated, leading to the amplitude maximums below $8 \mathrm{~km}$. To verify our speculation, the DT phases in every month in 2012 are presented in Fig. 5. Since the DT amplitudes were rather weak in the middle-mode height coverage, here we only provide the phase result in the height range of $3.5-9.0 \mathrm{~km}$. Clearly, the observed DT phase profiles correspond well with those from the MERRA data set "inst6_3d ana Nv", which resembles the MU radar observational results by Sakazaki et al. (2010) that the observed DT phase agrees well with that from the reanalysis data, while they clearly deviate from the GSWM-02 model results. For the zonal wind shown in Fig. 4, the DT amplitude has maximums at about $6 \mathrm{~km}$ in January and April, leading to much larger amplitudes than the GSWM-02 model results in the height range of 4-8 km. As presented in Fig. 5, in January, the phase has a turning point at about $7 \mathrm{~km}$. Below (above) this altitude, they exhibit downward (upward) phase progressions, corresponding to upward (downward) wave energy propagations, which likely implies the reflections of DT from both above and below $7 \mathrm{~km}$. DT energy gathers at this height, leading to the DT maximum. In April, the phase in the height range of 4-8 km was almost constant, indicating there a standing DT component does exist. As also shown in Fig. 4, for the meridional wind, the DT amplitude has maximums at about 5-6 km in January, February, April, and December and is much larger than the GSWM-02 model results in the height range of 4-7 km. In these four months, the phases in the height range of 4-7 km shown in Fig. 5 were all almost constant. Therefore, a standing DT structure arising from the reflection at the jet and ground surface was one of the primary causes for the larger DT amplitude below $8 \mathrm{~km}$. The background in the winter months around the tropospheric jet tends to cause DT reflection because of (1) strong eastward wind in the winter and spring months and because (2) the tropospheric jet was below the tropopause, where the background temperature would decrease with height, leading to small buoyant frequency, which is likely to cause wave reflection. In summary, our results suggest that the background wind and temperature could be a crucial cause for tidal height and season variability. However, in summer months (June, July, and August), when the eastward zonal wind is very weak or even westward, the phases exhibit traveling wave characteristics and are close to the GSWM-02 model results.

\section{Short-term variability of tides}

In order to completely understand tides, including high harmonics, e.g., the semidiurnal tide (ST), terdiurnal tide (TT), and quarterdiurnal tide (QT), and further explore their shortterm variability, we calculated the shifting Lomb-Scargle periodograms over a sliding $48 \mathrm{~h}$ window with increments of $2 \mathrm{~h}$ from the evenly interpolated winds at each height. We checked throughout our results and found that the short-term variability (magnitude variation on a timescale of up to several days) of tides was frequent, and a prominent enhancement of DT occurring around the jet height could be observed in May 2012. It is interesting that this enhancement was not present at the height range of $5-7 \mathrm{~km}$, where the maximums of monthly averaged DT occurred, but rather at the heights near the tropospheric jet where the monthly averaged DT was very weak, and not in January, when the tidal amplitude is largest, but rather in May, when the amplitude is moderate. Here we presented the results at $13.34 \mathrm{~km}$ in May 2012 (Fig. 6). For the zonal wind during days 20 to 23, it can be seen that not only the DT but also the high harmonics of tides, i.e., the ST, TT, and QT, were strengthened greatly. For clear demonstration, we provided the day-to-day amplitude variations in the four tidal components DT, ST, TT, and QT in Fig. 7. The largest amplitude of DT/ST/TT/QT can reach 6.6/5.3/3.7/3.7 $\mathrm{m} \mathrm{s}^{-1}$. Such strong TT and QT in the troposphere have seldom been reported before. Moreover, in 

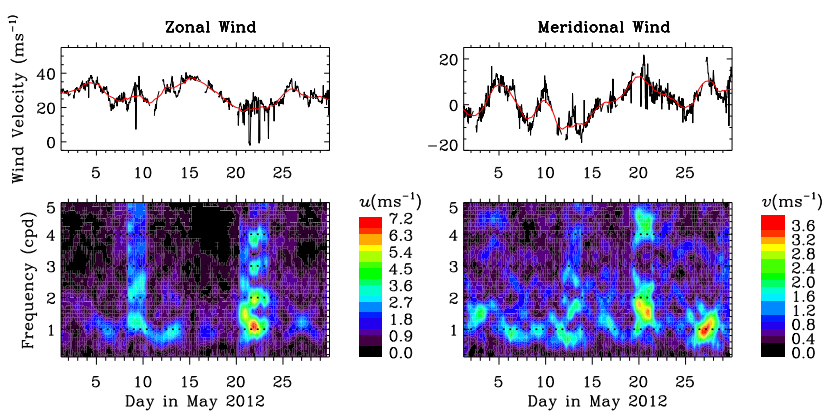

Figure 6. The zonal (left) and meridional (right) winds (upper) and their shifting spectra (lower) at $13.34 \mathrm{~km}$ in May 2012. The 2-day averages of winds are denoted by red curves in the upper panel.

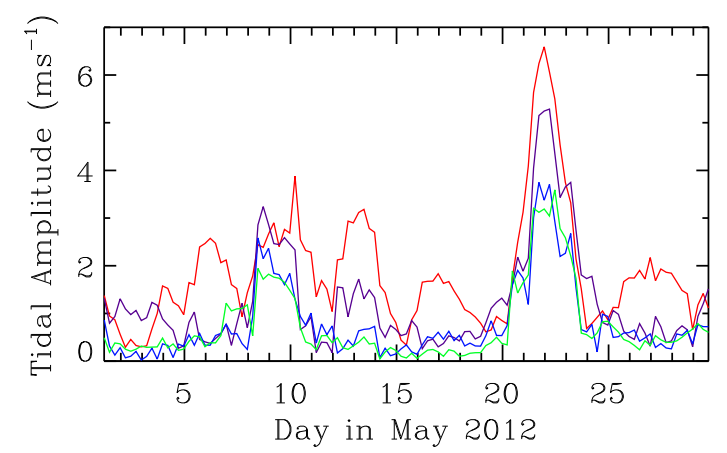

Figure 7. Amplitude variations in the four tidal components DT (red), ST (purple), TT (blue), and QT (green).

our data, strong TT and QT could only be found during the time when the DT was evidently enhanced. The DT, ST, TT, and QT displayed consistent and dramatic short-term variability. At day 21.7, very strong tidal oscillations, including the DT, ST, TT, and QT, were present. However, before and after that time, these tides were very weak and the smallest amplitude approximately attenuated to zero. The DT in the meridional wind also shows prominent short-term variability, and the largest amplitude is $3.6 \mathrm{~m} \mathrm{~s}^{-1}$ at about day 27 , while the smallest one is close to zero. It is worth noting that these four components of tides showed almost completely consistent variations, implying that they were excited by the same dramatically varying tidal source rather than modulated by the background wind because there was only moderate background zonal wind and rather weak meridional wind, and no dramatic variation in background wind was observed. On the other hand, at this height and in the enhancement period, we did not find any evidence of interactions among tides by correlation analysis of tidal amplitudes, nor did we between tides and other waves by bispectral analysis. However, we cannot identify the exact source here.
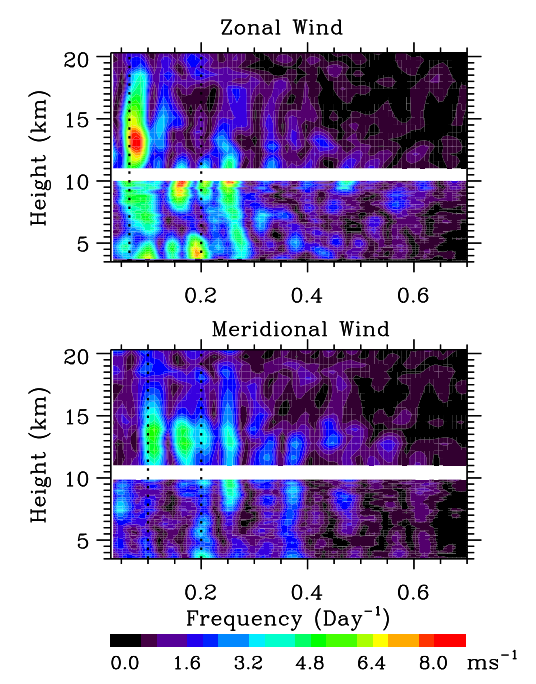

Figure 8. The same as Fig. 3 except that the displaying period range is from 1.5 to 30 days. The maximum spectral magnitudes for the zonal and meridional winds are 8.74 and $5.72 \mathrm{~m} \mathrm{~s}^{-1}$, respectively. The vertical dotted lines denote the exact 16-day and 5-day periods in the zonal wind and the exact 10-day and 5-day periods in the meridional wind.

\section{DT variability from the coupling with PWs}

As suggested by previous investigations (Beard et al., 1997, 1999, 2001; Mayr et al., 2005a, 2005b; Huang et al., 2009, 2012), the coupling between PWs and tides can also lead to tidal variability. For identifying the PW signatures, we detrended the raw time series for each month at each height by subtracting a linear background in time domain and performed a Lomb-Scargle periodogram analysis on the resultant time series. We checked the results in all 12 months in 2012, and found that significant PWs were present in each month and clearly stronger than the DT in the same month. Moreover, the PW and DT oscillations were both strong in April and their coupling was remarkable, which will be discussed later. Figure 8 shows the frequency spectra for observations in April 2012. The top and bottom panels are for the zonal wind and meridional wind disturbances, respectively. It can be clearly seen from this figure that prevailing oscillations exist with periods of several days in both zonal and meridional winds.

We refer to the quasi-16/10/5-day planetary wave as an oscillation within the period range of about 12-20/8-12/47 days (e.g., Williams and Avery, 1992; Luo et al., 2000; Grytsai et al., 2005; Riggin et al., 2006), and therefore keep the term of "quasi-16/10/5-day wave" even if the measured period differs. The quasi-5-day oscillation can be recognized from both the zonal (5.29-day) and meridional (5.04-day) winds. Hereinafter it is referred to as the quasi-5-day PW (QFDPW). Additionally, the most dominant planetary oscillation is the quasi-16-day (12.92-day) oscillation in the zonal wind and the quasi-10-day (8.92-day) oscillation in 


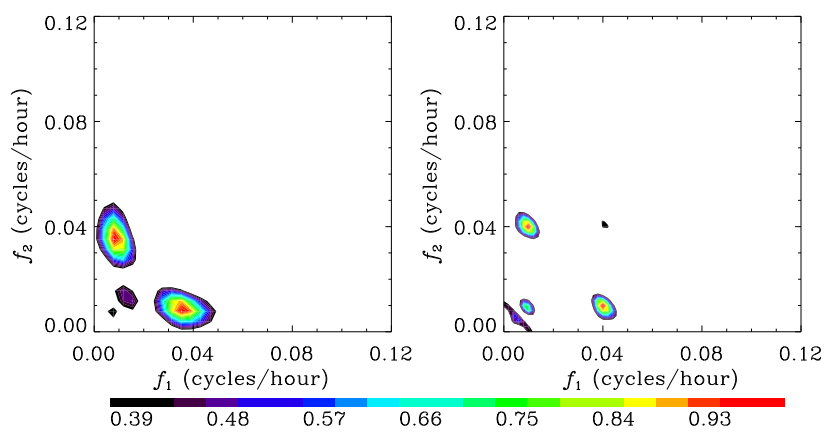

Figure 9. Bispectra for (left) zonal and (right) meridional winds at $5.51 \mathrm{~km}$ in April 2012.

the meridional wind. In our previous radiosonde observations (Huang et al., 2009), similar planetary oscillations could also be seen in the summer and winter months at middle latitudes, but their exact periods were a little different. In the zonal wind, the significant amplitudes of the quasi-16-day wave appear in the height range of $5.5-18.5 \mathrm{~km}$ and the largest amplitude is $8.7 \mathrm{~m} \mathrm{~s}^{-1}$ at $13.34 \mathrm{~km}$, while in the meridional wind, those of the quasi-10-day wave occur in the height range of $11-17.5 \mathrm{~km}$, and the largest one is $5.7 \mathrm{~m} \mathrm{~s}^{-1}$ at $13.92 \mathrm{~km}$. The QFDPW appears in the height range of 3.5-6.0 km and $8.5-11.5 \mathrm{~km}$ in the zonal wind, while it appears in the height range of $3.5-18.5 \mathrm{~km}$ in the meridional wind.

The generation of secondary waves (Pancheva, 2006) and the modulation of tide by PWs are usually taken as two indications for the PW-tide coupling. If a tide with frequency $f_{1}$ and a PW with frequency $f_{2}$ have sufficiently large amplitudes, the sum and difference interactions, i.e., the interactions among the wave triplet $\left(f_{1}, f_{2}, f_{1}+f_{2}\right)$ and $\left(f_{1}, f_{2}, f_{1}-\right.$ $f_{2}$ ), respectively, would likely occur simultaneously. Since the period of the PW is comparatively longer than that of the tide, the periods of the generated waves may be very close to that of the tide. The spectral peaks of secondary waves at the two sideband periods can be found in Fig. 3 and the exact periods are 30 and $20 \mathrm{~h}$, respectively, which correspond exactly to the oscillations periods of the secondary waves excited by the sum and difference interactions between the DT and QFDPW. This indicates the existence of nonlinear tide-PW interactions. Moreover, the bispectra for the zonal wind at the height range of 4.495-6.38 km and for the meridional wind at the height range of $4.06-5.51 \mathrm{~km}$ all display peaks corresponding to the interaction between DT and QFDPW. We use conventional "Fourier-type" methods to obtain the bispectral estimates by ensemble averaging. The bispectral plots are normalized by dividing by the maximum value, leading to relative amplitude between 0 and 1 . Figure 9 shows the bispectra for zonal and meridional winds at $5.51 \mathrm{~km}$. The peaks corresponding to the interaction between DT and QFDPW can be clearly observed both in the zonal and meridional winds. Through combining the two red diamonds represent-

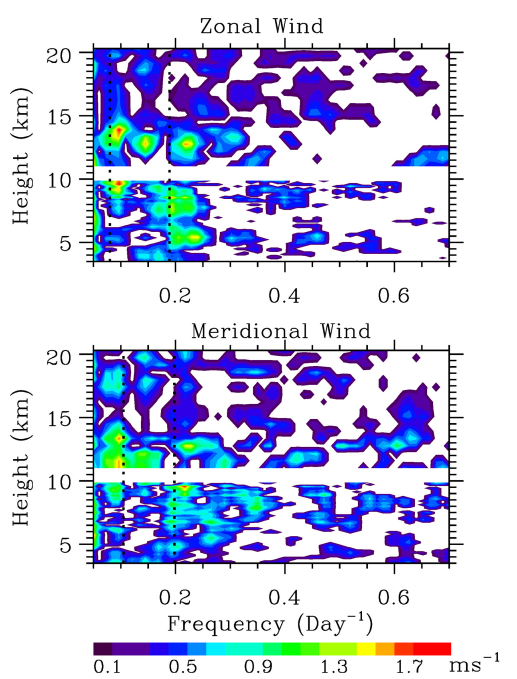

Figure 10. Lomb-Scargle periodogram of the diurnal tidal amplitude in April 2012. The maximum spectral magnitudes for the zonal and meridional winds are 1.83 and $1.68 \mathrm{~m} \mathrm{~s}^{-1}$, respectively. The spectral peaks for the PW modulation periods (12.92 and 5.29 days in the zonal component, and 8.92 and 5.04 days in the meridional component) are marked by dotted vertical lines.

ing the sidelobes at $5.51 \mathrm{~km}$ in Fig. 3, we can confirm the occurrence of this interaction.

In addition to the excitation of secondary waves, the tidal amplitude variability at the periods of PWs (i.e., tidal modulation by PWs) is taken as another symptom of the coupling between tides and PWs (Beard et al., 1999; Pancheva, 2000; Pancheva et al., 2002). For directly displaying the influence of PWs on tides, here we provide the periodograms of diurnal tidal amplitude in April 2012. We harmonically fit the diurnal oscillations over a sliding $24 \mathrm{~h}$ window with increments of $30 \mathrm{~min}$. In the harmonic fit, the interpolated points corresponding to time gaps larger than $6 \mathrm{~h}$ are ignored, and no fit was attempted if less than $16 \mathrm{~h}$ of data is present in any $24 \mathrm{~h}$ window, i.e., two-thirds of the window length (Beard et al., 1999). Fortunately, in any $24 \mathrm{~h}$ window, there are enough data points to accomplish the fit, producing continuous DT amplitudes and phases at a half-hour interval. Next, we carried out a Lomb-Scargle periodogram analysis on the timedependent tidal amplitude. Figure 10 evidently shows the 5day, 10-day, and 16-day PW modulations (only the values with confidence levels greater than $90 \%$ are shown), which further confirms the occurrence of interactions between the diurnal tide and the PWs. It should be noted that the exact periods and the heights of PW modulation were consistent with the corresponding periods and heights of PW oscillation; for example, the strongest 16-day PW modulation in the zonal wind occurred at the height range of $12-15 \mathrm{~km}$, where the 16-day PW oscillation was the strongest.

Generally speaking, the interactions between DT and PWs can lead to the short-term variability of DT. The interactions 
have two indications. The first is the generation of secondary waves from the sum and difference interactions. During these interactions, wave energy is exchanged among the primary waves, i.e., DT and PWs, and secondary waves. Since the DT is one of the energy-exchange participants, its energy varies. The variation in DT energy would lead to variation in DT amplitude. Moreover, the simultaneous energy exchange might be irreversible (Zhang and Yi, 2004; Huang et al., 2012) and thus the variation in DT amplitude is very complicated. Accordingly, the characteristic time of DT amplitude variation might be indeterminate and unable to reflect the period of the involved PW. The second indication is the modulation of DT by PWs. This is the modulation of a high-frequency wave by a low-frequency wave. During the modulation, the amplitude of DT would vary with the periods of the PWs. There might be other possible mechanisms for the short-term variability of DT, e.g., the day-to-day variations in the mean wind (Merzlyakov et al., 2001), interactions with wave modes and gravity waves (Liu et al., 2007, 2008), and tropospheric convective activity (Eckermann, 1997). However, the characteristic time of DT amplitude variation matching to the PW periods, together with bispectral analysis, confirms that the short-term variability of DT is at least partly caused by the interactions between DT and PWs.

\section{Summary}

Using observation data from the WHU VHF radar in 2012, we studied the primary features of the DT and its variability in the lower atmosphere over Chongyang. The main results of this paper are summarized as follows.

Through use a Lomb-Scargle periodogram analysis, we identify dominant diurnal oscillations in the lower atmosphere over Chongyang. As revealed by previous intensive radiosonde observations, the observed monthly averaged DT displays fairly significant height variations: in the lower stratosphere (above $17 \mathrm{~km}$ ), the observed wind amplitude profiles agree well with the models but show obvious departure below $9 \mathrm{~km}$, where the observed amplitudes are evidently larger than the model predictions. The remarkable maximums below $8 \mathrm{~km}$ in the winter and spring months are likely a common characteristic for the DT at middle latitudes, and the DT always shows a standing wave structure near the heights of the maximums, which might be the result of the reflection at the tropospheric jet and ground surface. Our results suggest that the background wind could be a crucial cause of tidal height and season variability.

The observed DT also displays significant short-term variability, especially in May 2012. During days 20 to 23 in May, not only the DT but also the higher harmonics of tides, i.e., the ST, TT, and QT, were strengthened greatly. Such strong TT and QT in the troposphere have seldom been reported before. These four components of tides showed almost completely consistent variations, implying that they were excited by the same dramatically varying tidal source rather than modulated by the background wind because there was only moderate background zonal wind and rather weak meridional wind, and no dramatic variation in background wind was observed in the dramatic DT enhancement duration.

Obvious quasi-5-day, 10-day, and 16-day PWs are recognized from our observations in 2012. Our analyses reveal that the DT/QFDPW sum and difference interactions took place at some altitudes in April. During the interactions, the DT exhibited evident short-term variability due to the irreversible energy exchange associated with the sum and difference interactions among DT and PWs. Moreover, we also found that the quasi-5-day, 10-day, and 16-day PWs can modulate the DT. During the modulation, the amplitude of DT would vary with the periods of the PWs.

In summary, our observations indicate dominant diurnal oscillations exist in the lower atmosphere at middle latitudes, and the DT shows remarkable height, season, and short-term variability. The background wind could be responsible for DT height and season variability. The short-term variation in the tidal source and the coupling with PWs could be responsible for DT short-term variability.

Acknowledgements. The WHU VHF radar was supported by the Meridian Space Weather Monitoring Project. This work was jointly supported by the National Basic Research Program of China (grant 2012CB825605), the National Natural Science Foundation of China (grants 41221003, 41174126, and 41374152), the Specialized Fund for Comprehensive Study and Evaluation of the Polar Environment (grant CHINARE2014-02-03), the Specialized Research Fund for the Doctoral Program of Higher Education of China (grant 20100141110020), the Ocean Public Welfare Scientific Research Project of the State Oceanic Administration of the People's Republic of China (grant 201005017), and the Open Program of the State Key Laboratory of Space Weather. We thank the Global Modeling and Assimilation Office (GMAO) and the Goddard Earth Sciences Data and Information Services Center (GES DISC) for the dissemination of MERRA.

The topical editor V. Kotroni thanks J. Xu and one anonymous referee for help in evaluating this paper.

\section{References}

Alexander, M. J.: Interpretations of observed climatological patterns stratospheric gravity wave variance, J. Geophys. Res., 103, 8627-8640, 1998.

Alexander, M. J. and Pfister, L.: Gravity wave momentum flux in the lower stratosphere over convection, Geophys. Res. Lett., 22, 2029-2032, 1995.

Batista, P. P., Clemesha, B. R., Tokumoto, A. S., and Lima, L. M.: Structure of the mean winds and tides in the meteor region over Cachoeira Paulista, Brazil $\left(22.7^{\circ} \mathrm{S}, 45^{\circ} \mathrm{W}\right)$ and its comparison with models, J. Atmos. Sol.-Terr. Phy., 66, 623-636, 2004.

Beard, A. G., Mitchell, N. J., Williams, P. J. S., Jones, W., and Muller, H. G.: Mesopause region tidal variability observed by meteor radar, Adv. Space Res., 20, 1237-1240, 1997. 
Beard, A. G., Mitchell, N. J., Williams, P. J. S., and Kunitake, M.: Nonlinear interactions between tides and planetary waves resulting in periodic tidal variability, J. Atmos. Sol.-Terr. Phy., 61, 363-376, 1999.

Beard, A. G., Williams, P. J. S., Mitchell, N. J., and Muller, H. G.: A spectral climatology of planetary waves and tidal variability, $\mathrm{J}$. Atmos. Solar-Terr. Phy., 63, 801-811, 2001.

Beldon, C. L. and Mitchell, N. J.: Gravity wave-tidal interactions in the mesosphere and lower thermosphere over Rothera, Antarctica $\left(68^{\circ} \mathrm{S}, 68^{\circ} \mathrm{W}\right)$, J. Geophys. Res., 115, D18101, doi:10.1029/2009JD013617, 2010.

Chandrasekhar Sarma, T. V., Kodama, Y.-M., and Tsuda, T.: Characteristics of atmospheric waves in the upper troposphere observed with the Gadanki MST Radar-RASS, J. Atmos. SolarTerr. Phy., 73, 1020-1030, 2011.

Eckermann, S. D., Rajopadhyaya, D. K., and Vincent, R. A.: Intraseasonal wind variability in the equatorial mesosphere and lower thermosphere, J. Atmos. Sol-Terr. Phy., 59, 603-627, 1997.

Forbes, J. M., Hagan, M. E., Zhang, X., and Hamilton, K.: Upper atmosphere tidal oscillations due to latent heat release in the tropical troposphere, Ann. Geophys., 15, 1165-1175, doi:10.1007/s00585-997-1165-0, 1997.

Grytsai, A., Grytsai, Z., Evtushevsky, A., Milinevsky, G., and Leonov, N.: Zonal wave numbers $1-5$ in planetary waves from the TOMS total ozone at $65^{\circ} \mathrm{S}$, Ann. Geophys., 23, 1565-1573, doi:10.5194/angeo-23-1565-2005, 2005.

Hagan, M. E., Forbes, J. M., and Vial, F.: On modeling migrating solar tides, Geophys Res. Lett., 22, 893-896, 1995.

Hagan, M. E., McLandress, C., and Forbes, J. M.: Diurnal tidal variability in the upper mesosphere and lower thermosphere, Ann. Geophys., 15, 1176-1186, doi:10.1007/s00585-997-1176$\mathrm{x}, 1997$.

Hagan, M. E., Roble, R. G., and Hackney, J.: Migrating thermospheric tides, J. Geophys. Res., 106, 12739-12752, 2001.

Hagan, M. E. and Forbes, J. M.: Migrating and nonmigrating diurnal tides in the middle and upper atmosphere excited by tropospheric latent heat release, J. Geophys. Res., 107, 4754, doi:10.1029/2001JD001236, 2002.

Huang, C. M., Zhang, S. D., and Yi, F.: Intensive radiosonde observations of the diurnal tide and planetary waves in the lower atmosphere over Yichang $\left(111^{\circ} 18^{\prime} \mathrm{E}, 30^{\circ} 42^{\prime} \mathrm{N}\right)$, China, Ann. Geophys., 27, 1079-1095, doi:10.5194/angeo-27-1079-2009, 2009.

Huang, C. M., Zhang, S. D., Zhou, Q., Yi, F., and Huang, K. M.: Atmospheric waves and their interactions in the thermospheric neutral wind as observed by the Arecibo incoherent scatter radar, J. Geophys. Res., 117, D19105, doi:10.1029/2012JD018241, 2012.

Huang, C. M., Zhang, S. D., Yi, F., Huang, K. M., Zhang, Y. H., Gan, Q., and Gong, Y.: Frequency variations of gravity waves interacting with a time-varying tide, Ann. Geophys., 31, 17311743, doi:10.5194/angeo-31-1731-2013, 2013.

Huang, K. M., Liu, A. Z., Zhang, S. D., Yi, F., Huang, C. M., Gan, Q., Gong, Y., and Zhang, Y. H.: A nonlinear interaction event between a 16-day wave and a diurnal tide from meteor radar observations, Ann. Geophys., 31, 2039-2048, doi:10.5194/angeo31-2039-2013, 2013.

Kishore, P., Namboothiri, S. P., Igarashi, K., Gurubaran, S., Sridharan, S., Rajaram, R., and Ratnam, M. V.: MF radar observations of 6.5-day wave in the equatorial mesosphere and lower thermosphere, J. Atmos. Sol.-Terr. Phy., 66, 507-515, 2004.

Liu, H.-L., Li, T., She, C.-Y., Oberheide, J., Wu, Q., Hagan, M. E., Xu, J., Roble, R. G., Mlynczak, M. G., and Russell III, J. M.: Comparative study of short-term diurnal tidal variability, J. Geophys. Res., 112, D18108, doi:10.1029/2007JD008542, 2007.

Liu, X., Xu, J., Liu, H.-L., and Ma, R.: Nonlinear interactions between gravity waves with different wavelengths and diurnal tide, J. Geophys. Res., 113, D08112, doi:10.1029/2007JD009136, 2008.

Luo, Y., Manson, A. H., Meek, C. E., Meyer, C. K., and Forbes, J. M.: The quasi 16-day oscillation in the mesosphere and lower thermosphere at Saskatoon $\left(52^{\circ} \mathrm{N}, 107^{\circ} \mathrm{W}\right), 1980-1996$, J. Geophys. Res., 195, 2125-2138, 2000.

Mayr, H. G., Mengel, J. G., Talaat, E. R., Porter, H. S., and Chan, K. L.: Mesospheric non-migrating tides generated with planetary waves: I. Characteristics, J. Atmos. Sol.-Terr. Phy., 67, 959-980, 2005a.

Mayr, H. G., Mengel, J. G., Talaat, E. R., Porter, H. S., and Chan, K. L.: Mesospheric non-migrating tides generated with planetary waves: II. Influence of gravity waves, J. Atmos. Sol.-Terr. Phy., 67, 981-991, 2005b.

McLandress, C.: Interannual variations of the diurnal tide in the mesosphere induced by a zonal-mean wind oscillation in the tropics, Geophys. Res. Lett., 29, 1305, doi:10.1029/2001GL014551, 2002.

Merzlyakov, E. G., Portnyagin, Yu. I., Jacobi, C., Mitchell, N. J., Muller, H. G., Manson, A. H., Fachrutdinova, A. N., Singer, W., and Hoffmann, P.: On the longitudinal structure of the transient day-to-day variation of the semidiurnal tide in the mid-latitude lower thermosphere - I. Winter season, Ann. Geophys., 19, 545562, doi:10.5194/angeo-19-545-2001, 2001.

Pancheva, D. V.: Evidence for nonlinear coupling of planetary waves and tides in the lower thermosphere over Bulgaria, J. Atmos. Sol.-Terr. Phy., 62, 115-132, 2000.

Pancheva, D., Merzlyakov, E., Mitchell, N. J., Portnyagin, Y., Manson, A. H., Jacobi, C., Meek, C. E., Luo, Y., Clark, R. R., Hocking, W. K., MacDougall, J., Muller, H. G., Kurschner, D., Jones, G. O. L., Vincent, R. A., Reid, I. M., Singer, W., Igarashi, K., Fraser, G. I., Fahrutdinova, A. N., Stepanov, A. M., Poole, L. M. G., Malinga, S. B., Kashcheyev, B. L., and Oleynikov A. N.: Global-scale tidal variability during the PSMOS campaign of June-August 1999: interaction with planetary waves, J. Atmos. Sol.-Terr. Phy., 64, 1865-1896, 2002.

Pancheva, D. V.: Quasi-2-day wave and tidal variability observed over Ascension Island during January/February 2003, J. Atmos. Sol.-Terr. Phy., 68, 390-407, 2006.

Pirscher, B., Foelsche, U., Borsche, M., Kirchengast, G., and Kuo, Y.-H.: Analysis of migrating diurnal tides detected in FORMOSAT-3/COSMIC temperature data, J. Geophys. Res., 115, D14108, doi 10.1029/2009JD013008, 2010.

Ramkumar, T. K., Niranjan kumar, K., and Mehta, S. K.: Mesosphere-stratosphere-troposphere radar observations of characteristics of lower atmospheric high-frequency gravity waves passing through the tropical easterly jet, J. Geophys. Res., 115, D24109, doi:10.1029/2009JD013733, 2010.

Riggin, D. M., Kudeki, E., Feng, Z., Sarango, M. F., and Lieberman, R. S.: Jicamarca radar observations of the diurnal and semidiur- 
nal tide in the troposphere and lower stratosphere, J. Geophys. Res., 107, 4062, doi:10.1029/2001JD001216, 2002.

Riggin, D. M., Liu, H.-L., Lieberman, R. S., Roble, R. G., Russell III, J. M., Mertens, C. J., Mlynczak, M. G., Pancheva, D. , Franke, S. J., Murayama, Y., Manson, A. H., Meek, C. E., and Vincent, R. A.: Observations of the 5-day wave in the mesosphere and lower thermosphere, J. Atmos. Sol.-Terr. Phy., 68, 323-339, 2006.

Sakazaki, T., Fujiwara, M., and Hashiguchi, H.: Diurnal variations of upper-tropospheric and lower-stratospheric winds over Japan as revealed with middle and upper atmosphere radar $\left(34.85^{\circ} \mathrm{N}\right.$, $\left.136.10^{\circ} \mathrm{E}\right)$ and five reanalysis data sets, J. Geophys. Res., 115 , D24104, doi:10.1029/2010JD014550, 2010.

Sasi, M. N., Ramkumar, G., and Deepa, V.: Tidal wind oscillations in the tropical lower atmosphere as observed by Indian MST Radar, Ann. Geophys., 19, 991-999, doi:10.5194/angeo-19-9912001, 2001.

Scargle, J. D.: Studies in astronomical time series analysis, II - Statistical aspects of spectral analysis of unevenly spaced data, Astrophys. J., 263, 835-853, 1982.

Seidel, D. J., Free, M., and Wang, J.: Diurnal cycle of upper-air temperature estimated from radiosondes, J. Geophys. Res., 110, D09102, doi:10.1029/2004JD005526, 2005.

Tsuda, T., Murayama, Y., Wiryosumarto, H., Harijono, S. W. B., and Kato, S.: Radiosonde observations of equatorial atmosphere dynamics over Indonesia, 1, Equatorial waves and diurnal tides, J. Geophys. Res., 99, 10491-10505, 1994a.

Tsuda, T., Murayama, Y., Wiryosumarto, H., Harijono, S. W. B., and Kato, S.: Radiosonde observations of equatorial atmosphere dynamics over Indonesia, 2, Characteristics of gravity waves, J. Geophys. Res., 99, 10506-10516, 1994b.

Vaughan, G. and Worthington, R. M.: Inertia-gravity waves observed by the UK MST radar, Q. J. Roy. Meteor. Soc., 133, 179188, doi:10.1002/qj.142, 2007.

Wallace, J. M. and Hartranft, F. R.: Diurnal wind variations, surface to 30 kilometers, Mon. Wea. Rev., 97, 446-455, 1969.

Wallace, J. M. and Tadd, R. F.: Some further results concerning the vertical structure of atmospheric tidal motions within the lowest 30 kilometers, Mon. Wea. Rev., 102, 795-803, 1974.
Williams, C. R. and Avery, S. K.: Analysis of long-period waves using the mesosphere-stratosphere-troposphere radar at poker flat, Alaska, J. Geophys. Res., 97, 20855-20861, 1992.

Zhang, S. D. and Yi, F.: A numerical study on the propagation and evolution of resonant interacting gravity waves, J. Geophys. Res., 109, D24107, doi:10.1029/2004JD004822, 2004.

Zhang, S. D. and Yi, F.: Latitudinal and seasonal variations of inertial gravity wave activity in the lower atmosphere over central China, J. Geophys. Res., 112, D05109, doi:10.1029/2006JD007487, 2007.

Zhang, S. D., Yi, F., Huang, C. M., and Chen, Z. Y.: Intensive radiosonde observations of gravity waves in the lower atmosphere over Yichang $\left(111^{\circ} 18^{\prime} \mathrm{E}, 30^{\circ} 42^{\prime} \mathrm{N}\right)$, China, Ann. Geophys., 26, 2005-2018, doi:10.5194/angeo-26-2005-2008, 2008.

Zhang, S. D., Yi, F., Huang, C. M., and Huang, K. M.: High vertical resolution analyses of gravity waves and turbulence at a mid-latitude station, J. Geophys. Res., 117, D02103, doi:10.1029/2011JD016587, 2012.

Zhang, S. D., Yi, F., Huang, C. M., Huang, K. M., Gan, Q., Zhang, Y. H., and Gong, Y.: Latitudinal and altitudinal variability of lower atmospheric inertial gravity waves revealed by U.S. radiosonde data, J. Geophys. Res., 118, doi:10.1002/jgrd.50623, 2013.

Zhang, X., Forbes, J. M., Hagan, M. E., Russell III, J. M., Palo, S. E., Mertens, C. J., and Mlynczak, M. G.: Monthly tidal temperatures 20-120 km from TIMED/SABER, J. Geophys. Res., 111, A10S08, doi:10.1029/2005JA011504, 2006.

Zhang, X., Forbes, J. M., and Hagan, M. E.: Seasonal-latitudinal variation of the eastward-propagating diurnal tide with zonal wavenumber 3 in the MLT: Influences of heating and background wind distribution, J. Atmos. Sol.-Terr. Phy., 78-79, 37-43, 2012.

Zhao, Z. Y., Zhou, C., Qing, H. Y., Yang, G. B., Zhang, Y. N., Chen, G., and Hu, Y. G.: Wuhan Atmosphere Radio Exploration (WARE) radar: System design and online winds measurements, Radio Sci., 48, 326-333, doi:10.1002/rds.20040, 2013. 